\title{
Diversitas Journal
}

ISSN 2525-5215

DOI: $10.17648 /$ diversitas-journal-v 1 i2.472

Volume 1, Número 2 (mai./ago. 2016 ) pp: 148-155. www.kentron.ifal.edu.br/index.php/diversitas_journal (C) Diversitas Journal

\section{Rendimento de biomassa em diferentes populações de plantas do cultivar de milho Zea mays L. AG 1051 nas condições de sequeiro no agreste alagoano}

\author{
Dacio Rocha Brito ${ }^{(1)}$; Renato de Almeida Silva ${ }^{(2)}$; Ane Caroline da Silva Santos ${ }^{(3)}$
}

Página | 148

(1)Professor - Orientador do Curso de Ciências Biológicas - UNEAL - daciobrito@hotmail.com (2)Graduando do Curso de Ciências Biológicas- Universidade Estadual de Alagoas- Arapiraca- Alagoas renatoalmeidabio@gmail.com; (3)Graduanda do Curso de Ciências Biológicas - UNEALanne.ok@live.com

Todo o conteúdo expresso neste artigo é de inteira responsabilidade dos seus autores.

Recebido em: 20 de fevereiro de 2016; Aceito em: 20 de março de 2016; publicado: 06 novembro 2016. Copyright@ Autor, 2016.

RESUMO: O estudo foi realizado no Polo Agroalimentar de Arapiraca, município de Arapiraca, região agreste do estado de Alagoas, caracterizada por ter um período chuvoso curto, que ocorre principalmente nos meses de maio, junho e julho. A finalidade foi testar o crescimento e o desenvolvimento de nova cultivar de milho (Zea mays L.) AG 1051 introduzida na região, em condições de sequeiro, relacionando esse crescimento e desenvolvimento à competição por nutrientes e água do solo. A motivação surgiu em razão da necessidade de conhecer o desempenho agrícola de plantas de grande importância para a região, e utilizadas comumente na alimentação humana e animal. As plantas foram cultivadas em três espaçamentos diferentes deixando o stand com uma população de 104.166, 125.000 e 156.250 plantas/ha. Verificou-se, também, a produção de órgãos das plantas submetidas à adubação em épocas diferentes. Foram avaliadas produção de biomassa total na época de colheita para formação de silagem, bem como a produção de folhas e do caule. Avaliou-se ainda a produção de grãos na época de colheita dos mesmos, conforme indicação do produtor de sementes. Uma maior população de plantas promoveu, no geral, um maior rendimento de biomassa das plantas e da maioria dos órgãos estudados, mesmo existindo a possibilidade de uma maior competição por nutrientes e água no solo, levando a ponderar sobre o uso de grandes populações de plantas de milho por hectare como forma de aumentar o rendimento da biomassa mesmo nas condições de sequeiro na região agreste de Alagoas.

Palavras-chave: plantas forrageiras, semiárido, densidade populacional.

ABSTRACT: The study was conducted at the Polo Agrifood Arapiraca, Agreste region of Alagoas state, characterized by a short rainy season, which occurs mainly in the months of May, June and July. The purpose was to test the growth and development of new cultivar of corn (Zea mays L.) introduced in the region, under rainfed conditions, relating that growth and development to competition for nutrients and water from the soil. The motivation arose because of the need to study the agricultural performance of corn plants in the region, used commonly in food and feed. The plants were grown in three different spacing, with populations of 104,166, 125,000 and 156,250 plant per hectare. During testing it was found, also, the production of plant organs subjected to fertilization at different times. Was evaluated total biomass at harvest to form silage, as well as the production of leaf and stalk. Was also evaluated the production of grain at harvest thereof, as indicated by the seed producer. In general, a larger population of plants promotes a higher yield of biomass and organs vegetables, even with the possibility of greater competition for nutrients and water in the soil. Leading to ponder the use of large populations of plants of maize per hectare in order to increase the yield of biomass even under rainfed conditions in the Agreste region of Alagoas.

Keywords: forage plants, semiarid region, population density. 


\section{INTRODUÇÃO}

Realizado em Arapiraca, região agreste de Alagoas, região caracterizada por ter um período chuvoso curto, que ocorre entre os meses de maio e julho, com a finalidade de testar o crescimento e o desenvolvimento desses cultivares, em condições de sequeiro, relacionando esse crescimento a competição por nutrientes e água do solo. A motivação surgiu em razão da necessidade de cultivo de plantas na região utilizadas comumente na alimentação humana e animal. Durante os estudos foram avaliadas a produção das plantas a partir do fornecimento de adubação em épocas diferentes e populações diferentes de plantas, foram avaliadas produção de biomassa total na época de colheita para formação de silagem, produção de folhas, produção da caule e produção de grãos.

De maneira geral, o melhor arranjo de plantas é aquele que promove distribuição mais uniforme de plantas por área, o que possibilita melhor utilização dos fatores edafoclimáticos. Qualquer fator que interfira na fotossíntese compromete o acúmulo de matéria seca na parte aérea da planta, e, por conseguinte, a produção de grãos (BERGONCI et al., 2001).

O Polo Tecnológico Agroalimentar de Arapiraca se situa na região agreste de Alagoas, local do plantio, que por sua vez sofre com falta d'água em algumas épocas do ano e ultimamente com o inverno chegando cada vez mais tardio e com menos precipitação pluviométrica as plantas sofrem com a falta d'água. Após o plantio e posteriormente emergência das plântulas, foi feito o desbaste para que a população de plantas ficasse conforme o planejado e que evidenciasse a possibilidade de competição por nutrientes e água presentes no solo.

Para o melhor desempenho da cultura do milho, a escolha do melhor arranjo de plantas na área e a definição da melhor época para aplicação da cobertura nitrogenada estão entre as decisões mais importantes, aliadas à escolha do híbrido e da época de semeadura (BORGES et al., 2006). A manipulação do arranjo de plantas em milho, através de alterações na densidade de plantas, de espaçamentos entre linhas, de distribuição de plantas na linha e na variabilidade entre plantas, é uma das práticas de manejo mais importantes para maximizar a interceptação da radiação solar, otimizar o seu uso e potencializar o rendimento de grãos (ARGENTA et al., 2001a). 


\section{PROCEDIMENTOS METODOLÓGICOS}

A semeadura do milho (Zea mays L) ocorreu no dia 15 de abril de 2016, anteriormente e no mesmo dia fez-se a adubação de fundação em parte dos tratamentos, conforme recomendação das análises de solo. Foi utilizado o uso de agrotóxico para o combate de formigas no dia 17. A emergência aconteceu no dia 20 de abril, no dia 23/04 foi realizada a primeira capina. A adubação de cobertura, em todas as parcelas, ocorreu no dia 10 de maio do referido ano, sendo que as parcelas que não receberam adubação de fundação, receberam uma quantidade maior de adubo, de tal forma que o total de fertilizante foi igual para todas as parcelas. A área total do experimento foi de $1.500 \mathrm{~m}^{2}$, que foi divida em parcelas, onde instalou-se o experimento. Os tratamentos foram: $\mathrm{A}_{1} \mathrm{E}_{1}$, $\mathrm{A}_{1} \mathrm{E}_{2}, \mathrm{~A}_{1} \mathrm{E}_{3}, \mathrm{~A}_{2} \mathrm{E}_{1}, \mathrm{~A}_{2} \mathrm{E}_{2}$ e $\mathrm{A}_{2} \mathrm{E}_{3}$, sendo $\mathrm{A}_{1}$ com adubação de fundação e adubação de cobertura e $\mathrm{A}_{2}$ com apenas adubação de cobertura, no total todos os tratamentos receberam a mesma quantidade de adubo. $\mathrm{E}_{1}$ é espaçamento de 0,08 m entre plantas e 0,80 entre linhas, $\mathrm{E}_{2}$ é espaçamento de 0,10 m entre plantas e 0,80 m entre linhas e $\mathrm{E}_{3}$ é espaçamento de 0,12 m entre plantas e 0,80 m entre linhas. $\mathrm{O}$ surgimento da maior parte das flores acorreu dia 06 de junho. Para cada tratamento foram retiradas 20 plantas como amostra na época de colheita para formação de silagem, cada planta foi pesada e seus órgãos foram retirados e pesados separadamente, inclusive as inflorescências. Os dados obtidos foram tabulados e analisados, os resultados foram plotados em gráficos para melhor compreensão.

\section{RESULTADOS E DISCUSSÃO}

Observou-se um maior rendimento médio de biomassa total do milho AG 1051 para o tratamento com adubação de fundação, com uma produção de $83.531 \mathrm{Kg} / \mathrm{ha}$, quando comparado com o tratamento sem adubação de fundação, onde o rendimento médio de biomassa foi igual a $69.805 \mathrm{Kg}$ /ha (Figura 1). De acordo com Sangoi (2000), a população ideal para maximizar o rendimento de grãos de milho varia de 30.000 a 90.000 plantas.ha-1 ${ }^{-1}$ dependendo da disponibilidade hídrica, fertilidade do solo, ciclo do cultivar, época de semeadura, espaçamento entre linhas e segundo Cruz et al (2007), o número ideal de plantas por área é variável, uma vez que a planta de milho altera o rendimento de grãos de acordo com o grau de competição intraespecífica proporcionado pelas diferentes densidades de plantas. Logo, apesar dos dados anteriores estarem 
relacionados com rendimento de grãos, observa-se variações no rendimento das culturas com mudanças na população e no caso em questão a adubação de fundação, como um dos fatores influenciadores do rendimento e considerando que para cada população os demais fatores de produção não foram alterados, pode-se inferir que a adubação de fundação foi fundamental para uma maior produção, independentemente da população.

Figura 1. Rendimento de biomassa do milho AG 1051, em condições de sequeiro com adubação de fundação (A1) e sem adubação de fundação (A2) e em populações diferentes.

Arapiraca 2016.

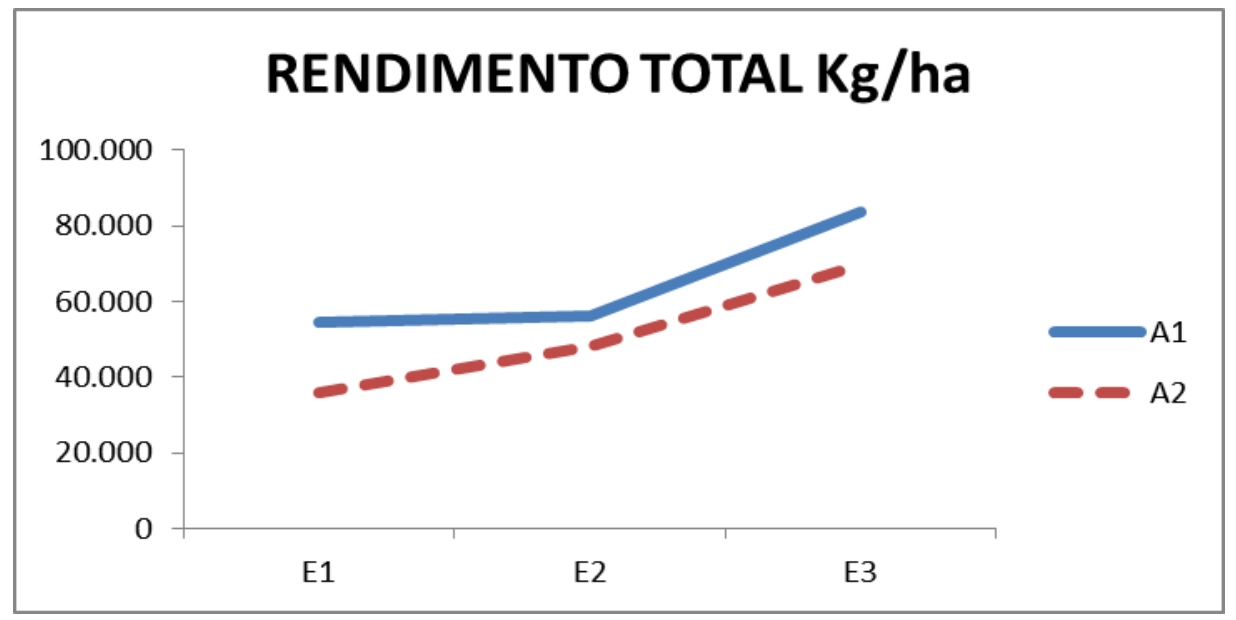

Observou-se, também, um maior peso da inflorescência masculino no tratamento onde não houve adubação de fundação, para maiores populações de plantas, cujo resultado pode ser observado na Figura 2. Esse resultado diverge das demais variáveis estudadas, onde observou-se maiores rendimentos também para peso do colmo, das folhas e peso das espigas em espaçamentos entre plantas menor, ou seja, em população menor.

Segundo Sangoi (2000), um o número de indivíduos por área maior que a densidade ótima, pode acarretar em uma série de consequências negativas na formação da espiga, podendo levar à esterilidade. Pode ser devido a diferenciação da espiga ser retardada em relação à diferenciação do pendão e em espigas diferenciadas tardiamente ocorre uma taxa reduzida de crescimento, transformando poucos primórdios de espiguetas em floretes funcionais durante a floração o que pode diminuir o número de espiguetas que serão fertilizadas devido à falta de coincidência entre antese e espigamento. No experimento em questão observou-se redução no peso das flores masculinas e aumento no peso das espigas em populações menores, caracterizando influência negativa da população na inflorescência masculino e positiva no peso da espiga, indicando que mesmo ocorrendo uma redução do peso da inflorescência 
masculino não afetou o rendimento de peso das espigas, caracterizando que a quantidade de pólen foi adequada a fecundação nas flores femininas. Esse resultado nos leva a ponderar sobre a necessidade de maiores investigações nas condições ambientais estudadas.

Figura2. Rendimento da inflorescência masculina do milho AG 1051, em condições de sequeiro com e sem adubação de fundação e em populações diferentes. Arapiraca 2016

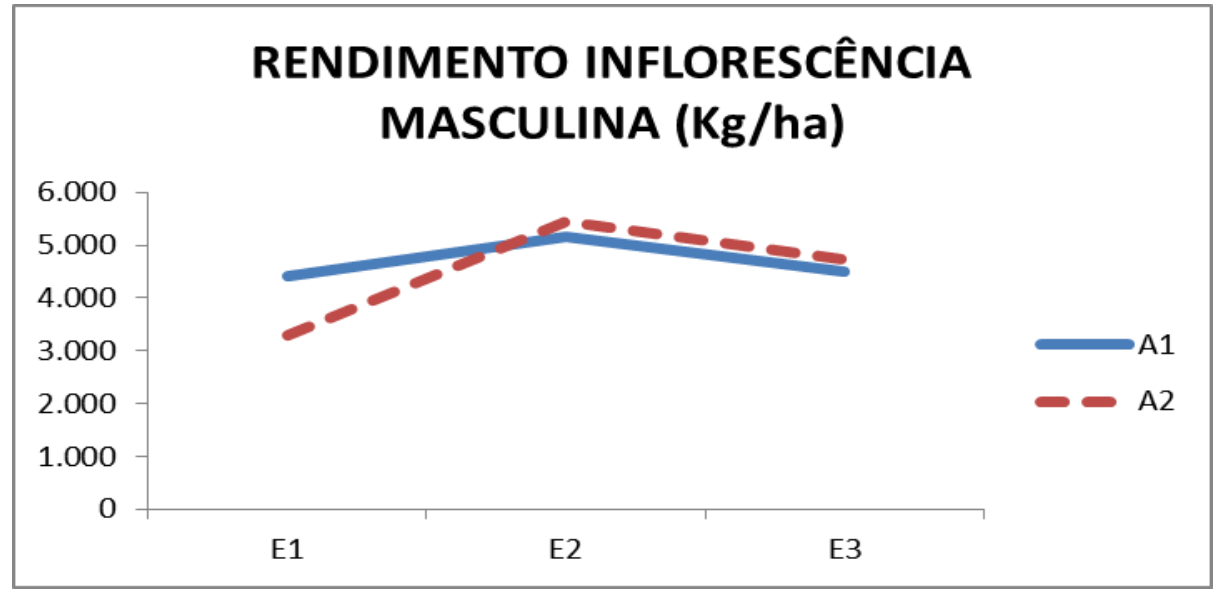

Para rendimento de colmo, folha e espiga observou-se rendimentos satisfatório, levando em consideração a baixa precipitação pluviométrica ocorrida durante o período de cultivo (Figuras 3, 4 e 5). Esse resultados originaram o maior rendimento de biomassa total, conforme (Johnson et al., 1998; Molin, 2000), afirmam que, um aumento de população causa um menor rendimento, em razão do aumento na interceptação de luz e do melhor aproveitamento da água e nutrientes disponíveis, acréscimos na produtividade podem ser obtidos pelo aumento da densidade de semeadura, associado à redução do espaçamento entre linhas. A redução da competição inter e intraespecífica por esses fatores de produção, obtida pelo melhor arranjo espacial entre as plantas, dá-se pelo aumento da área foliar por unidade de área, a partir dos estádios fenológicos iniciais

Com uma maior população de plantas existe uma maior competição por água e nutrientes do solo, o que pode afetar o crescimento e desenvolvimento das plantas, que por sua fez influencia o rendimento de biomassa, esses resultados são concordantes de acordo com Cruz et al., (2007), que citam que o aumento da densidade de plantas até determinado limite é uma técnica usada com a finalidade de elevar o rendimento de grãos da cultura do milho. Porém, o número ideal de plantas por área é variável, uma vez que a planta de milho altera o rendimento de grãos de acordo com o grau de competição intra-específica proporcionado pelas diferentes densidades de plantas. 
Figura 3. Rendimento de colmo do milho AG 1051, em condições de sequeiro, com e sem adubação de fundação e em populações diferentes. Arapiraca, 2016.

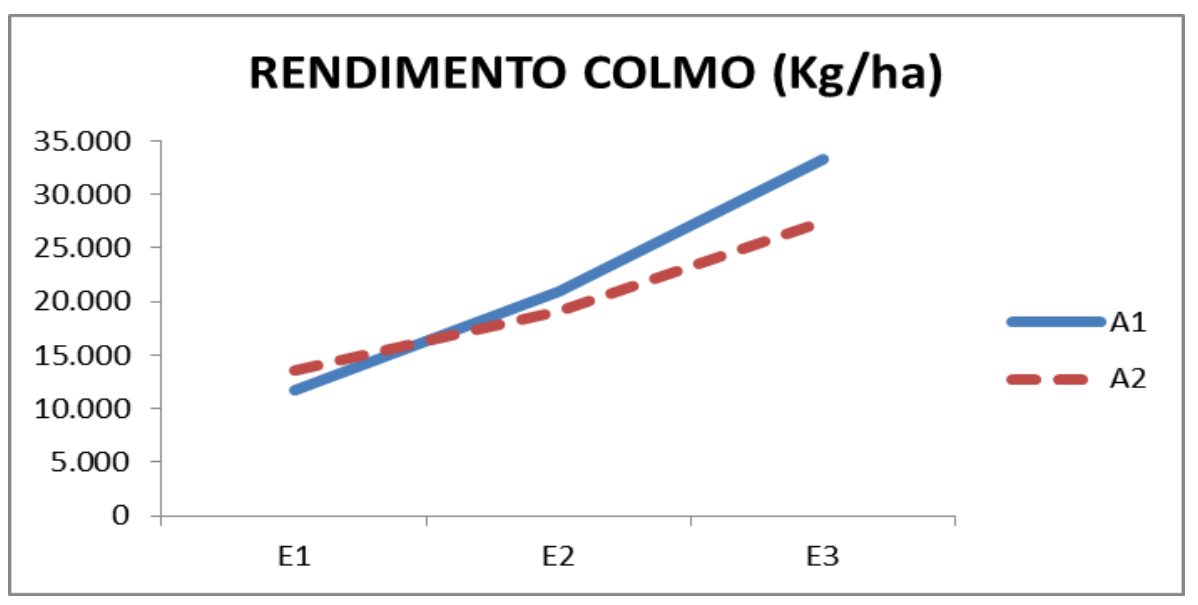

Página | 153

Figura 4. Rendimento de folhas do milho AG 1051, em condições de sequeiro, com e sem adubação de fundação e em populações diferentes. Arapiraca, 2016.

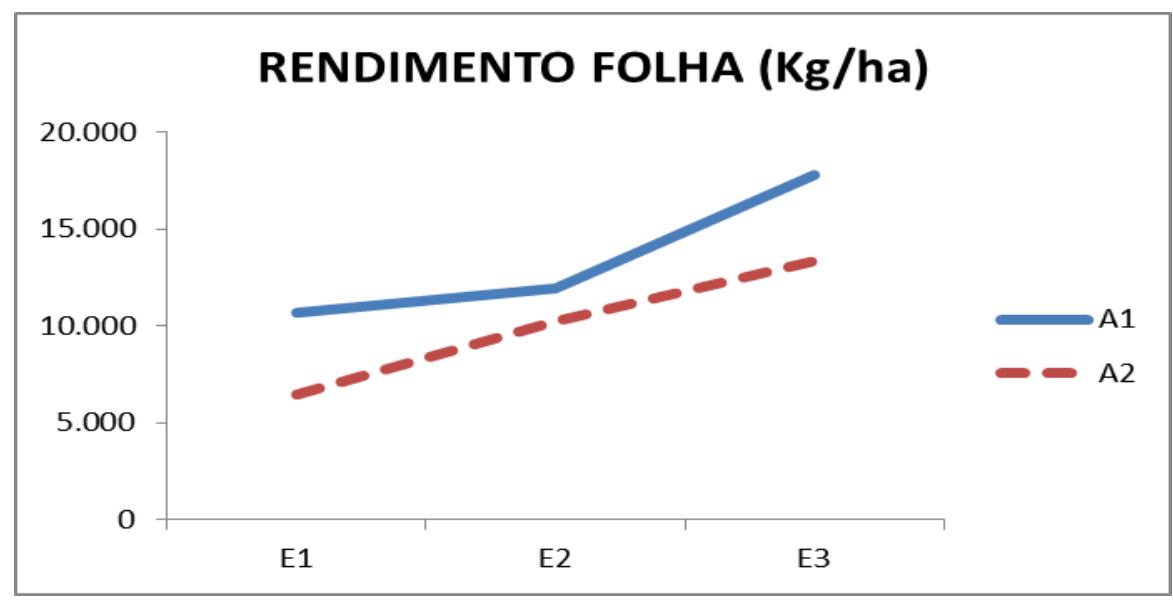

Figura 5. Rendimento de espigas do milho AG 1051, em condições de sequeiro, com e sem adubação de fundação e em populações diferentes. Arapiraca, 2016.

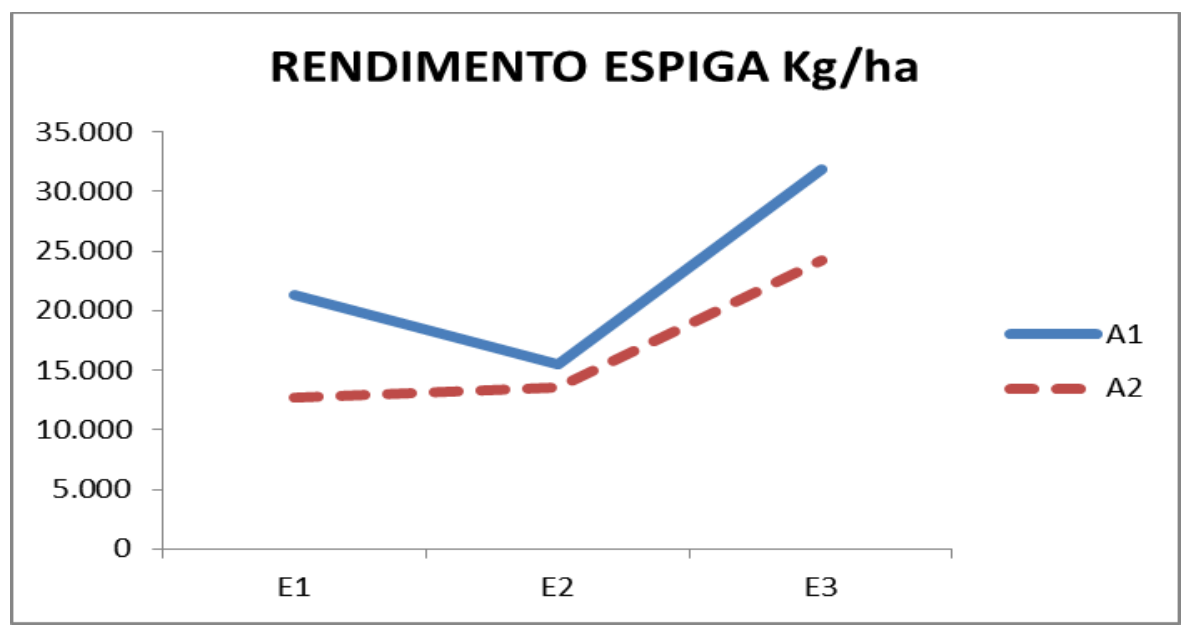


Observou-se, portanto, que com a adubação de fundação, as plantas tiveram a seu dispor uma maior disponibilidade de nutrientes e assim, houve um maior crescimento e desenvolvimento das mesmas, contribuindo para maiores rendimentos, mesmo com uma maior população de plantas, no caso do tratamento $\mathrm{A}_{1} \mathrm{E}_{3}$.

O arranjo mais favorável de plantas propiciado pela aproximação de linhas de semeadura pode estimular as taxas de crescimento da cultura no início do ciclo e, consequentemente contribuir para a produtividade do milho (SANGOI et al., 2009), no caso em questão não houve uma maior aproximação das linhas e sim uma maior aproximação das plantas nas linhas com aumento da população, o que, promoveu um menor rendimento final, isso, provavelmente, devido a uma maior competição por água e nutrientes com o aumento populacional, dentro de uma mesma distância entre linhas. Esse resultado leva a ponderar sobre novos estudos relacionados a arranjo diferentes de plantas dentro de uma mesma população e de populações de diferentes na região de estudo e em condições de sequeiro.

\section{CONCLUSÃO}

Conclui-se que é fundamental o uso de adubação de fundação para a cultura do milho na região agreste de Alagoas, mesmo aumentando a população de 104.166 plantas/ha para 156.250 plantas/ha e que se deve testar arranjos diferentes de plantas dentro de uma mesma população e de diferentes populações em condições de sequeiro na região agreste de Alagoas. Maiores populações de plantas, resultaram em menores rendimentos em condições de sequeiro no agreste alagoano, dentro das populações testadas no presente trabalho, exceto para peso de flores masculinas.

\section{REFERÊNCIAS}

1. AFFÉRRI, F. S., MARTins, E. P., PELUZiO J. M., FidELIS, R. R., RODRIGUES H. V. M. Espaçamento e densidade de semeadura para a cultura do milho, em plantio tardio, no estado do Tocantins Goiânia, GO, Brasil www.agro.ufg.br/pat ISSN 1517-6398 Pesquisa Agropecuária Tropical, v. 38, n. 2, p. 128-133, jun. 2008. Disponível em: 
<http://www.revistas.ufg.br/pat/article/viewFile/4174/3668 $>$. Acesso em: 10 de nov. de 2016.

2. ARGENTA, G.; SILVA, P.R.F.; SANGOI, L. Arranjo de plantas em milho: análise do estado-da-arte. Revista Ciência Rural, Santa Maria, v.31, n.6, p.10751084, dez., $2001 \mathrm{a}$.

3. BERGONCI, J. I.; BERGAMASCHI, H.; SANTOS, A. O.; FRANÇA, S.; RADIN, B. Eficiência da irrigação em rendimento de grãos e matéria seca de milho.

Pesquisa Agropecuária Brasileira, Brasília, v. 36, n. 7, p. 949-956, 2001.

Disponível em: < http://www.scielo.br/pdf/pab/v41n2/a08v41n2.pdf > . Acesso em: 10 out. 2016 .

4. BORGES, I. D.; VON PINHO, R. G.; PEREIRA, J. L. A. R.; ALVAREZ, C. G. D. Efeito das épocas de aplicação da cobertura nitrogenada, das fontes de nitrogênio e dos espaçamentos entre fileiras na cultura do milho. Revista Ceres, Lavras, v.53, p.75-81, 2006.

5. CRUZ, J. C.; PEREIRA, F. T. F.; PEREIRA FILHO, I. A.; OLIVEIRA, A. C.; MAGALHÃES, P. C. Resposta de cultivares de milho à variação em espaçamento e densidade. Revista Brasileira de Milho e Sorgo. Sete Lagoas, v.6, n. 1, p.60-73, 2007.

6. JOHNSON, G. A.; HOVERSTAD, T. R.; GREENWALD, R. E. Integrated weed management using narrow corn row spacing, herbicides, and cultivation.

Agronomy Journal, Madison, v. 90, n. 1, p. 40 - 46, 1998.

7. SANGOI, L. Understanding plant density effects on maize growth and development: an important issue to maximize grain yield. Ciência Rural, Santa Maria, v.31, n.1, p.159-168, 2000.

8. SANGOI, L.; SCHMITT, A.; SALDANHA, A.; FIORENTIN, C.F.; PLETSCH, A.J.; VIEIRA, J.; GATELLI, M.A. Rendimento de grãos de híbridos de milho em duas densidades de plantas com e sem a retirada dos perfilhos. Ciência Rural, v.39, p.325-33 1, 2009. Disponível em: <file:///C:/Users/NucleodeEstudosBot\%C3\%A2n/Downloads/27 1-5834-1PB.pdf>. Acesso em: 10 out.2016. 